\title{
THE VOLUNTEERED GEOGRAPHIC INFORMATION IN ARCHAEOLOGY
}

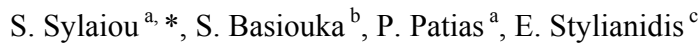

\author{
${ }^{a}$ Aristotle University of Thessaloniki, Department of Surveying Engineering, Greece - sylaiou@photo.topo.auth.gr, \\ patias@auth.gr \\ ${ }^{\mathrm{b}}$ National Technical University of Athens, School of Rural and Surveying Engineering, Greece - \\ s.basiouka@gmail.com \\ ${ }^{c}$ Aristotle University of Thessaloniki, School of Urban-Regional Planning and Development Engineering, Greece \\ sstyl@auth.gr
}

KEY WORDS: Crowdsourcing, Neogeography, Volunteered Geographic Information, Cultural Heritage, Archaeology

\begin{abstract}
:
The purpose of the paper is to investigate the Volunteered Geographic Information (VGI), which is still at a very early stage, to identify its use worldwide including characteristic examples and research its potential applications in Cultural Heritage andArchaeology as a new field for study. In the first part of the paper a brief review of the field is given, the international terminology and its components are analysed. The basic framework of VGI and the international research trends are presented as well. The second part deals with the applications of VGI in Cultural Heritage and Archaeology. Finally, some thoughts, conclusions and recommendations for action and institutionalization of use are offered underlining that VGI cannot be applied to Archaeology without professional attendance and supervision so as unwanted results can be prevented.
\end{abstract}

\section{INTRODUCTION}

Geographic Information Science is designed for storing, managing, analysing and presenting spatial information. As reported by Longley et al (2005) "almost everything that happens, happens somewhere. Knowing where something happens is critically important" as well as that "with a single collection of tools, GIS is able to turn from a curiosity-driven science to a practical problem-solving". Goodchild (1992) has introduced the term "Geographic Information Science" for issues raised around the technology that collects and manages spatial data in a technological manner. Two main reasons have contributed to that geographical revolution; web mapping and citizens' participation in data manipulation. (Basiouka 2010). GIS applications in Archaeology are not something new. One of the most important elements of archaeological information is its spatial dimension. Thus, archaeologists adopted quite early GIS, since both the residue of human activity from Prehistoric Era till nowadays, as well as the human way of thinking that created them, are both very closely tied to space and location (Kaimaris et al. 2011).

In recent years, a great revolution has taken place in GIS. The source, the use and the manipulation of spatial information have dramatically changed during the last decade. Terms like Neogeography (Turner 2006), Volunteered Geographic Information (Goodchild 2007), web - mapping (Plewe 2007), ubiquitous cartography (Gartner et al. 2007) were used to present the new trend in Geographic Information Science. Elwood (2008) states that there are different definitions that distinguish online spatial information into two main categories. In the first category, web-mapping and ubiquitous cartography can classify those terms, which emphasize not only the mapping itself, but also the practices that could be adopted, so as the online interactive mapping to become more attractive to new users. In the second category, the user-generated content and the volunteered geographic information concern the terms that focus on the spatial data, highlighting the source and the processes, through which they are created and used.

In archaeology, VGI can offer significant advantages, since non-expert enthusiasts can significantly contribute to the mapping archaeological data. This paper discusses both theoretically Volunteered Geographic Information as a new scientific trend, and practically, its contribution through numerous applications in a variety of disciplines emphasizing to Cultural Heritage. After a short introduction it follows a section that explores the field of the Volunteered Geographic Information. The next section is related to the main categories with some characteristic examples of VGI in Cultural Heritage. Finally, this study presents brief conclusions and future directions.

\section{THE VOLUNTEERED GEOGRAPHIC INFORMATION}

Neogeography allows users to use and manage geographic information and tools according to their interests without taking into account specific cartographic rules and mapping techniques. The users are as versatile as the medium itself allows them and inventive as the maps they produce. As Turner (2006) has underlined "Neogeography means "new geography" and consists of a set of techniques and tools that fall outside the realm of traditional GIS, Geographic Information Systems". The main revolution that has derived by this trend is that

\footnotetext{
* Corresponding author. This is useful to know for communication with the appropriate person in cases with more than one author.
} 
everyone can be involved by collecting and uploading data or by editing entries and monitoring the results. In terms of participation, use, manipulation and editing geographical information has been fundamentally democratized (Haklay, 2013).

Crowdsourcing is related to the wisdom of the crowd, as Surowiecki (2004) states in the Wisdom of the Crowds: Why the Many are Smarter than the Few. In the case of spatial information that is generated by users (User Generated Content) (Sieber 2007) or the spatial information derived from the crowd (Crowdsourcing), the information and its origin must be controlled and evaluated.

Volunteered Geographic Information (VGI) is one of the most widely deployed and disseminated terms. In its publication entitled "Citizens as sensors: The World of Volunteered Geography" Goodchild (2007) provides for the first time the term of VGI, indicating that now the participation of a large number of people, often with few qualifications, is widespread. Amateurs collect spatial information in a scientific area that for a long time was monopolized by official cartographic organizations. It is about an individual effort of amateurs who act voluntarily in GIS collection, editing and manipulation and their results may or may not be accurate, according to Goodchild. The main goal of the new field is the participation of the citizens; everyone can be involved by collecting and uploading data or by editing entries and monitoring the results; In other words in spatial data manipulation.

The term of "User Generated Content" is closer to what "Crowdsourcing" means. "Neogeography" is the whole philosophy behind this statement and "Volunteered Geographic Information" is the term which focuses on the spatial dimension of the field in accordance to the citizens importance.

However, the main question that is posed concerns the reasons that lead to that spatial revolution; Mobile phones have the central role in data collection by volunteers. According to the International Telecommunications Union 2011 statistics the two thirds $(2 / 3)$ of the global population does not have access to the Internet. In contrary, $87 \%$ has a mobile phone. The percentage of the population in developing countries which has a mobile phone rises in $79 \%$. Moreover, mobile GIS is a powerful tool that can provide the necessary updated and reliable digital spatial data, under crucial circumstances. . In this way, the obstacles (lack of funding, infrastructure, personnel, etc.) that existed for the creation and access to the necessary digital spatial information are eliminated. Thus all citizens are enabled to improve their living standards and all their life activities moving into a new world, the mWorld (mobile world), as it is called by the experts. Other reasons that also played a critical role at its dissemination are: low cost of data manipulation, elimination of time, the great number of participants and the transfer of citizens in an active role in aspects of spatial data collection and use. It is not irrelevant that Perkins and Dodge (2008) named as serious reasons the affordable computer power and the broadband internet for the exploitation of the geospatial information. According to the last study of the Greek information Society Observatory, internet penetration in Greece has reached $46 \%$ in 2009. There are a total of 2.105 .076 broadband connections as of early 2010 which approach the $18,6 \%$ of broadband penetration.

Nowadays, the scientific interest is focused on the evaluation of this information that can be directly collected by these means and the development in the widest possible range of applications, especially those that today require and cost a lot of time and money. Thus, among the various applications, modern technologies could encourage the active participation in funding (crowdfunding), conservation and presentation of cultural heritage that leads to the creation of a participatory culture and the democratization of knowledge, necessary processes in times of economic crisis.

World Wide Web (www) today contains as many dynamic maps and mashup maps, as the users' interests can create (Basiouka, 2010). However, there are three main areas of spatial information use based on voluntary participation by citizens. A survey (Coleman 2010) has classified citizen participation in three main categories; the first one meets the needs of the citizens for free spatial data unlike the commercial services, such as the commercial navigation maps; the second one is based on social networks and contains information of interest to those who collect them; and the third is based on governmental initiatives. The categorization is quite general and within these major categories many subcategories and overlap of content is included.

First category: The maps where the starting point for the creation and development is focused on the Volunteered Geographic Information. The most basic were the ones of Navigation - General Mapping. The use of the Volunteered Geographic Information tool started as a movement unlike the commercial navigation agencies, in order to reduce the cost of acquiring and upgrading data. An extraordinary example of a VGI application NASA asks the help of the public to improve Martian maps and assist Mars science teams studying data about the Red Planet (Figure 1).

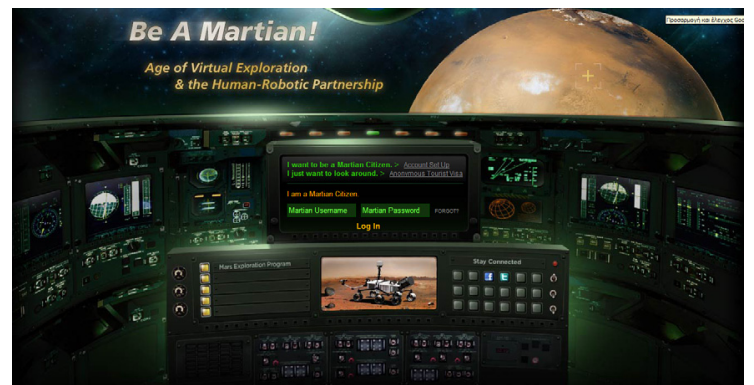

Figure 1: Be a Martian! Age of Virtual Exploration and the Human-Robotic Partnership

(http://beamartian.jpl.nasa.gov/welcome)

Second category: The maps that resulted through the increased Internet use in combination with the social networks. As Ethier (2003) reported the theory behind social networking is based on the study of these networks and the mapping of their relationships, as they can be applied to a wide range of groups, from small communities to entire nations. Characteristic examples of such maps are those that use the Flickr and generally are based on mashup maps, or the Ushahidi platform to crowdsource information using multiple channels, including SMS, email, Twitter and the web (Figure 2). 


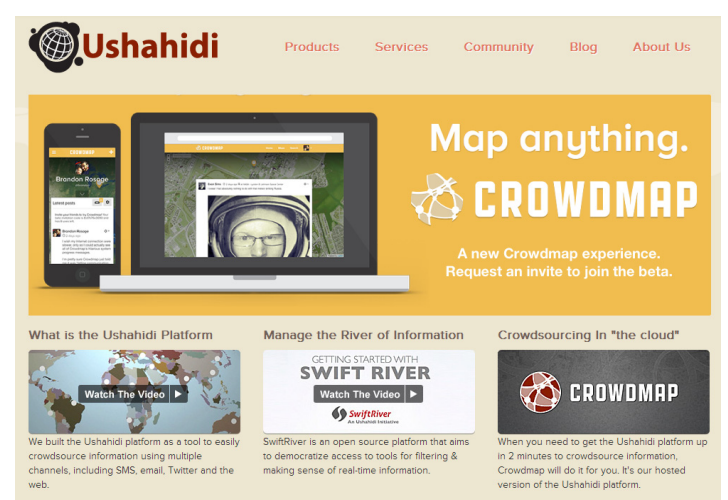

Figure 2: Ushahidi platform (http://ushahidi.com/)

Third category: the maps that arise as society's need to address small or large problems of local or global scale (e.g. crisis management), may involve even the entire planet and developed with the help of awareness among citizens. Climate scientists asked the crowd help to classify over 30 years of tropical cyclone satellite imagery. The global intensity record contains uncertainties caused by differences in analysis procedures around the world and through time. Scientists are enlisting the public because patterns in storm imagery are best recognized by the human eye (Figure 3).

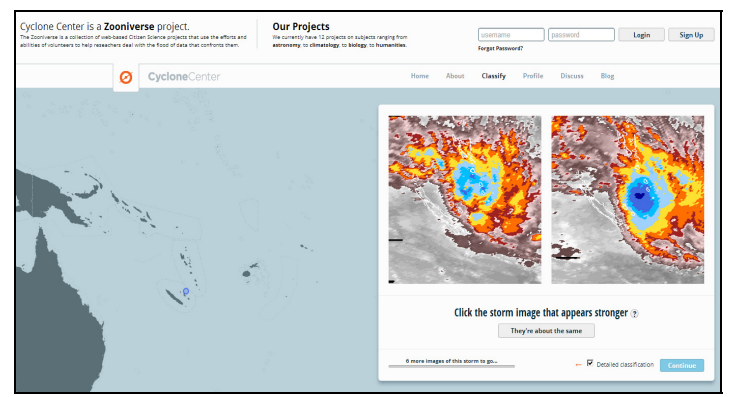

Figure 3: Cyclone Center (http://www.cyclonecenter.org/\#/classify)

The use of VGI is dynamic, because varies throughout the years and often overlaps between the different categories in the technology development.

\section{VOLUNTEERED GEOGRAPHICAL INFORMATION AND CULTURAL HERITAGE}

Although even scientific programs with strict specifications from major organizations such as NASA and SETI have data in crowdsourcing applications, archaeologists are still a bit reluctant to use this technology (Sylaiou et al. 2013). This article presents the preliminary results of a survey about the applications Volunteered Geographic Information in Archaeology. Below are presented the main categories and some representative examples.

\section{(A) Archaeological sites detection}

Multispectral satellite images of high resolution can be used for the detection of archaeological sites. This, apart from being a significant innovation, it is a challenge due to the huge data in cases of large geographic areas. The Voluntary Geographic Information allows to the crowd to participate in these surveys, put tags on selected items considered to be of scientific interest and provide solutions to archaeological research questions. A typical example is the platform created by the University of California in collaboration with the Department of Digital National Geographic Society to search for the tomb of Genghis Khan (Huynh et al. 2012). A crowdsourcing platform has allowed hundreds of scientists - WWW visitors to participate in the research in progress and analyse numerous multispectral high resolution satellite images of the Northern Mongolia region, which are covered. Within a year, the participants created more than two million notes in about $6.000 \mathrm{klm}^{2}$, which include lakes, rivers and potential archaeological sites. Then the notes were grouped based on the traces' density and in it was observed that in the points where there were many tags, there was high probability of antiquities discovery. The survey was completed by sending a team of scientists for survey the areas that were detected. With the help of tablets, it has collected relevant to archaeological sites information. In the National Geographic webpage there was a video with instructions on how you can discern ancient structures to satellite images and create tags (Figure 7).

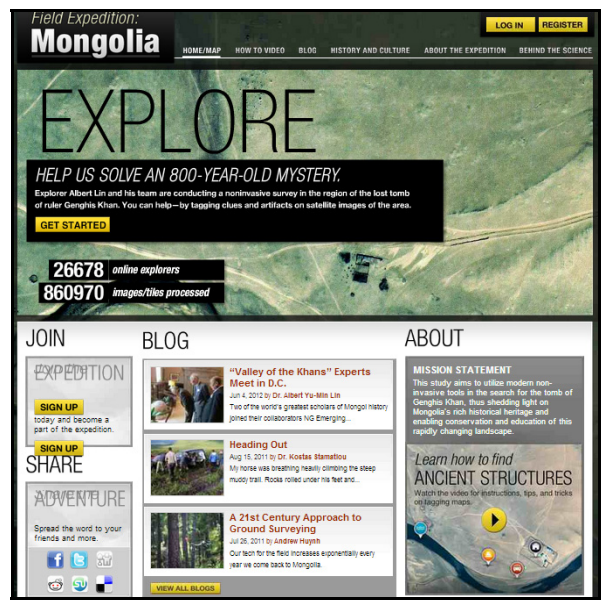

Figure 7: Project website

[http://exploration.nationalgeographic.com/mongolia]

(B) Historical maps georeferencing and rectification

British Library implemented a pilot research program related to geo-referencing of historical maps. More specifically, selected maps of the 17th, 18th and 19th century from England, Wales and London were scanned and georeferenced from volunteers ${ }^{1}$. In the project website detailed instructions and an explanatory video were mentioned with the steps that should be followed by volunteers for georeferencing the maps ${ }^{2}$. The results of this effort were published in the JISC-funded Old Maps Online portal. The names of participants with the highest contribution to the project were published in the project website ${ }^{3}$. The success of the pilot study led the responsible to proceed with the digitization and distribution of more maps via Internet (Kowal and Pridal 2012).

Similarly, the next application, called "New York Public Library's Map Rectifier Project" is related to the correction of historical maps4. It is an online environment that allows the crowd to correct old historic maps from the collection of the Public Library of New York, so that they have the accuracy of current maps (Figure 8). Besides the explanatory video on the

\footnotetext{
1 British Library, Help us place our digitized maps, http://www.bl.uk/maps/index.html 2 ibid.

${ }^{3}$ Participants, http://www.bl.uk/maps/georeferencingdata.html

4 NYPL Map Warper, A New York Public Library website, http://maps.nypl.org/warper/
} 
steps that should be followed, the volunteers were given the opportunity to browse and study the maps that were georeferenced by volunteers. The result of this effort were transcriptions 8,700 maps in four months and the acquisition of the 2012 Cutting Edge Technology in Library Services Award from the Office of Information Policy of the American Library Association.

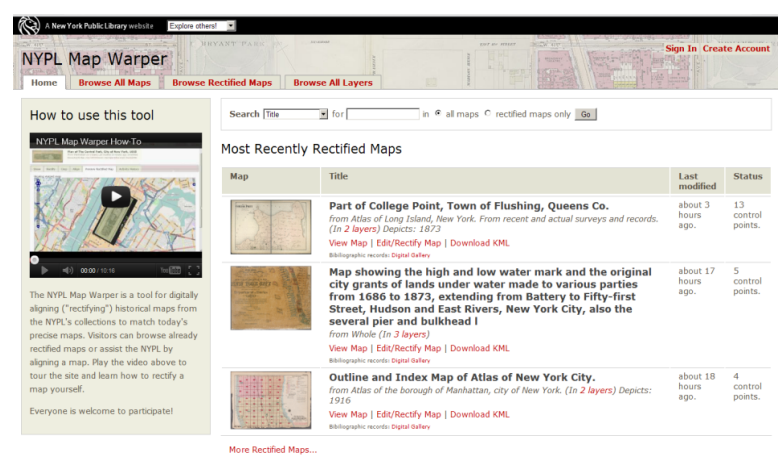

Figure 8: New York Public Library's Map Rectifier Project [http://maps.nypl.org/warper/]

(C) Combating illicit trafficking of antiquities.

WikiLoot (Figure 9) is a crowdsourcing platform that aims to identify antiquities that are products of illegal excavations. Its founder, Jason Felch has consulted open source software specialists to create the site, lawyers for legal issues and experts in social networks for how he can involve the public ${ }^{5}$.

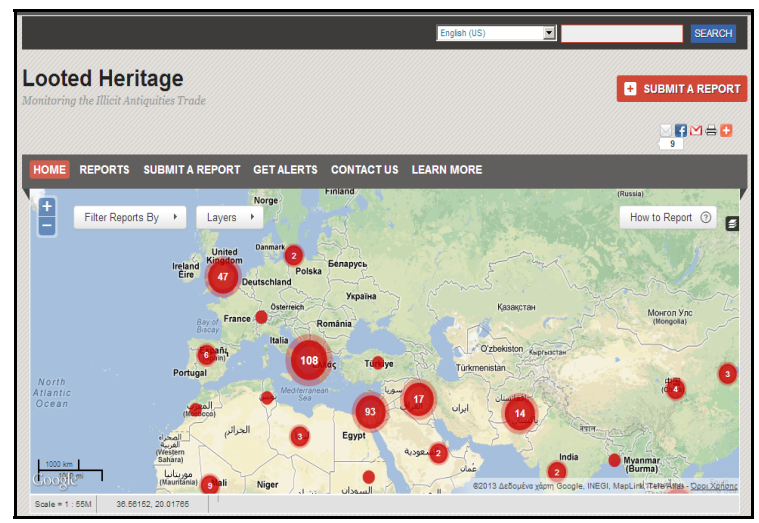

Figure 9: WikiLoot [https://heritage.crowdmap.com/]

\section{(D) Use the information to create 3D Web GIS.}

The Department of Geography, University of Heidelberg is implementing the research program MayaArch3D (Schwerin et al. 2012) that has to do with the creation of the Maya archaeological site of Copan in Honduras virtual models, a monument of UNESCO World Cultural Heritage, and its publication on the Internet. One of the research program objectives is to explore the creation and visualization of threedimensional models of cities and landscape by crowdsourcing information.

\section{(E) Archaeological research questions solving}

Another research project explored the hypothesis if the castles were constructed to be fortresses or mansions. The project website provided to virtual visitors the opportunity (a) to explore through a simplified three-dimensional model with spaces formed as they used to be in the $14^{\text {th }}$ century, (b) to observe the ways in which the castle leads visitors to its rooms and (c) to record their tracks in the virtual model castle.

(F) Recording of archaeological sites by volunteers.

Tourists visiting Greek islands during the summer months contribute to mapping through the Volunteer GIS, OpenStreetMap. Characteristic examples can be observed in the islands of archaeological interest, such as Crete, Rhodes, Kos and Ithaca. The information learned from the user logs are kept in the database system of the OpenStreetMap (Figure 10).

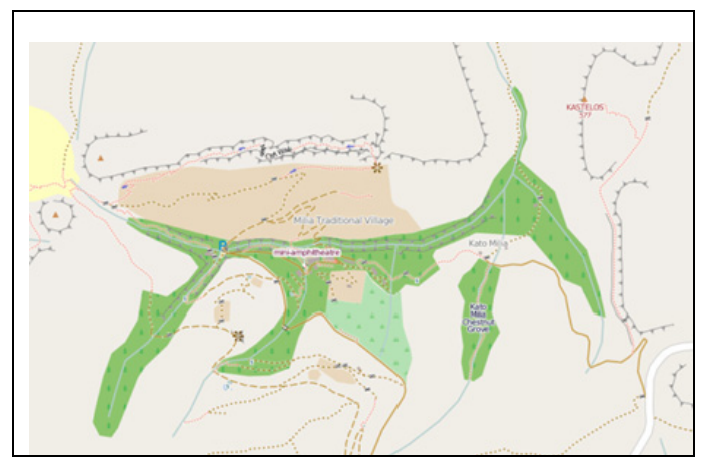

Figure 10: Archaeological sites mapped by volunteers [www.Openstreetmap.org];

\section{CONCLUSIONS AND FUTURE DIRECTIONS}

The Volunteered Geographic Information is a relatively new field that gathers considerable interest because of its main advantages, including: technology deployment, low cost, great participation of citizens, data instant gathering, dissemination of large amounts of spatial data and the possibility of improving the accuracy through multiple measurements (Haklay, et al. 2010). Scientific research has mainly focused on institutionalizing its use for various purposes and improving methods of assessment information collected for any purpose. Only in recent years the experimentation with crowdsourcing methods in the field of cultural heritage has begun. Early indications show that the VGI is expected to provide solutions to cultural organisations problems that have intensified due to the economic crisis over the recent years but it cannot be applied to Archaeology without professional attendance and supervision.

Using the cell phones technology, the www, the open source software, and the citizen participation many changes will be held and a new era will start up soon. In this context, the technology of Volunteered Geographic Information can contribute to digitization, documentation, and dissemination of cultural information. However, an institutional framework with specific rules for the use and exploitation of such information on the Internet and its dissemination to the general public must be created by experts, in order to avoid serious risks and future problems with antiquities.

\footnotetext{
5 WikiLoot aims to use crowdsourcing, Experiment will help to track down stolen ancient artefacts, http://www.archaiologia.gr/en/blog/2012/06/07/wikiloot-aims-touse-crowdsourcing/
} 
The use of the VGI in the services of cultural heritage can join in all three categories, according to the reason it serves:

- For the first category: simple navigation maps of archaeological sites, maps with paths leading to heritage sites as an extension of the plain navigation maps.

- For the second category: maps with points of interest (PoI) in historical cities, archaeological sites, monuments, museums that can be enriched with photographs and video / personal stories of visitors volunteers. Meaning that the navigation maps will be filled with attribute features based on volunteers' interests.

- For the third category: navigation maps where visitors volunteers identify problems (e.g. lack of information and infrastructure, dangerous points within the archaeological sites), speeding up the creation of archaeological cadastre e.g. by the use a large number of amateur photos to create threedimensional monuments' models.

However, the idea of having non-expert contributing to content is interesting and worth discussing in more detail. The question of the quality should be carefully addressed; There are some important questions to be answered. What kind of contribution is worthwhile? Is the main interest content or creation of a link between site and visitors? What are the incentives? In the field of Archaeology the recording and documenting is not desirable without the help of professionals. Internationally volunteers and laymen and all the people, who do not have research permission for a particular area, site or monument cannot collect survey information of archaeological sites. In case of sensitive data or non-excavated archaeological sites, not only special caution, but also careful institutionalization and standards concerning the use the VGI methods should be implemented, in order to avoid the increase of illegal excavations and / or destruction of antiquities. Volunteers can only work under a supervision of a professional archaeologist who has a permission to study an area or a site. The development of these crowdsourcing applications must be under the supervision of specialist teams.

The Volunteered Geographic Information is a fast developing and highly cost-effective solution. However, quality is inversely proportional to the amount of data derived. These data, which in many cases require specialized knowledge, are created by volunteers and not by experts. Therefore, incomplete, inaccurate data that cannot be used are created, but it is evident to be processed at a second project phase.

The need for participants in crowdsourcing projects has as a starting point the desire to contribute to a good cause and provide their contribution for the common good. Crowdsourcing applications must be designed carefully to give the impression that participants volunteer and are not working for free.

\section{REFERENCES}

Basiouka, S., (2010). "The use of dynamic maps and Volunteered Geographic Information in Greece" Proceedings (CD) of the FIG Commission 3 Annual Meeting on "Information and Land Management. A Decade after the Millennium”, Sofia, Bulgaria.

Coleman, D., 2010. Volunteered Geographic Information in Spatial Data Infrastructure: An Early Look at Opportunities and Constraints, In: Proceedings of GSDI 12 World Conference, Singapore.
Ethier, J. 2009. Current Research in Social Network Theory. Northeastern University College of Computer and Information Science.

Gartner, G., Bennett, D., \& Morita, T., 2007. Toward ubiquitous cartography. Cartography and Geographic Information Science, 34, pp. 247-257.

Goodchild, M., 1992. Keynote addresses: Geographical Information Science. In: Proceedings of the Fourth International Symposium on Spatial Data Handling, Zurich, July 1990, pp. 13-14 and EGIS 91. Brussels, April 1991, pp. 342-350.

Goodchild, M., 2007. Citizens as Sensors: The World of Volunteered Geography. Geo Journal 69, pp. 211-221

Haklay, M. M. (2013). Neogeography and the delusion of democratisation.Environment and Planning A, 45(1), 55-69.

Haklay, M. M., Basiouka, S., Antoniou, V., \& Ather, A. (2010). How many volunteers does it take to map an area well? The validity of Linus' law to volunteered geographic information. Cartographic Journal, 47(4), 315-322.

Harris T., 2012. Interfacing archaeology and the world of citizen sensors: exploring the impact of neogeography and volunteered geographic information on an authenticated archaeology. World Archaeology, 44(4), pp. 580-591

Huynh A. et al., 2012, Defining the Undefined. Harnessing the Power of Public Consensus in the Search for Genghis Khan's Tomb, NSF IGERT 2012 Video \& Poster Competition, http://posterhall.org/system/igert/igert2012/posters/252/presenta tions/igert-poster.pdf? 1335804477

Kaimaris D., Sylaiou S., Georgoula O., Patias P., 2011. GIS of Landmarks Management. Journal of Cultural Heritage, 10(4), pp. 520-528, Amsterdam: Elsevier.

Kowal K. C. and Pridal P., 2012. Online georeferencing for libraries: the British Library implementation of Georeferencer for spatial metadata enhancement and public engagement. Journal of Map \& Geography Libraries: Advances in Geospatial Information, Collections \& Archives, 8:3, pp. 276-289.

Longley, P., Goodchild, M., Maguire, D., Rhind, D., 2005. Geographic Information Systems and Science. John Wiley and sons Ltd., 517 pages.

Observatory for the Greek Information Society [2010] $11^{\text {th }}$ Broadband Report [online] Available at http://www.observatory.gr/page/default.asp?la=1\&id=2101\&pk $=440 \&$ return $=183$ [accessed October 2010]

Oomen, J., \& Aroyo, L. (2011). Crowdsourcing in the Cultural Heritage Domain: Opportunities and Challenges. In: Proceedings of the 5th International Conference on Communities and Technologies. 19 June -2 July, Brisbane (Australia).

OpenStreetMap [2012] Main page [online] Available at www.openstreetmap.org [accessed August 2012] 
Perkins, C., Dodge, M., 2008. "The potential of the usergenerated cartography: a case study of the OpenStreetMap project and Mapchester mapping party". North West Geography, 8(1):19-31

Plewe, B. 2007. Web cartography in the United States. Cartography and Geographic Information Science, 34, pp. 133136.

Schwerin J. von, Richards-Rissetto H., Agugiaro G., Remondino F., Girardi, G., 2012. The MayaArch3D Project: A 3D GIS Web System for Querying Ancient Architecture and Landscapes, Digital Humanities Conference 2012, http://www.dh2012.uni-

hamburg.de/conference/programme/abstracts/the-mayaarch3dproject-a-3d-gis-web-system-for-querying-ancient-architectureand-landscapes/

Sieber, R., 2007. Geoweb for social change. from http://www.ncgia.ucsb.edu/projects/vgi/supp.html (March 3, 2008)

Surowiecki J., 2004. The Wisdom of Crowds: Why the Many are Smarter than the Few, Little Brown.

Sylaiou S., Basiouka S., Potsiou C.., Patias P., 2013. Overview of Volunteered Geographic Information applications with

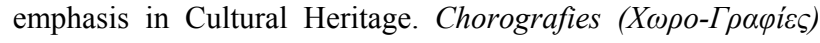
Journal (in Greek).

Turner, A. (2006). Introduction to neogeography. O'Reilly Media.

\section{ACKNOWLEDGEMENTS}

This study is supported by the postdoctoral scholarship "Aristia" from the Research Committee of the Aristotle University of Thessaloniki, Greece (Project: Crowdsourcing in Cultural Heritage).

The authors would like to thank Dr. Chryssy Potsiou and the reviewers of this paper for her useful comments and suggestions in the preliminary version of the paper. 